\title{
NUEVA VERSIÓN AUTÓGRAFA DE LA RIMA XVI
}

Iin nuestro libro La muijer ideal recoginos las principales cuestiones en torno al tema de la Proximidal del amado y su introducción en España, resumiendo las noticias y observaciones que G. Orton expuso sobre las fuentes, así como sobre las diferentes versiones, y concretando la influencia que el tema en general y el poema de Goethe Nähe des Gelicblin en particular, ejercieron sobre autores españoles, como E. IF. San\%, Arnao, Vicetto y Dacarrete, además de los chilenos Blest Gana y G. Matta ${ }^{1}$. Nos interesaba la suerte de este tema literario en España, porque sus huellas más importantes se encuentran en las Rimas de G. A. Bécquer. Dos de ellas lo tratan, la XVI y la XXVIII. 'También posee el mismo tema aquel otro poema, atribuido a Gustavo por Iglesias Figueroa, que comienza: "¿No has scntido en la nochc...?", pero debemos prescindir de él por hacerece cada vez más inverosimil esta atribución ${ }^{2}$.

De las dos Rimas, la XVI es más importante. A sus relaciones con el poema Nähe des Gelicbten de Goethe dedica Orton su atención, fijándose sobre todo en el metro alternante de versos endecasilabos y pentasílabos, suponiendo que podría haber surgido de una traducción del poema de Goethe, hecha por Arnao, que emplea el mismo metro, o bien de la finura de oído de Gustavo que habria captado el ritmo del poema alemán, al oirselo recitar, por ejemplo a E. F. Sanz, y trataria de imitarlo. Por nuestra parte, y en el mismo libro de La mujer ideal, analizábamos el metro de la Rima XVI, hallando que está montado sobre los versos pentasilabos, que riman

1 Véase para esto y lo que sigue, J. M. Dízz 'TAmonina, La mujer ideal. Aspectos y fuentes de las Rimas de G. A. Bécquer, Madrid, C. S. I. C., 1965. pp. 84-94.

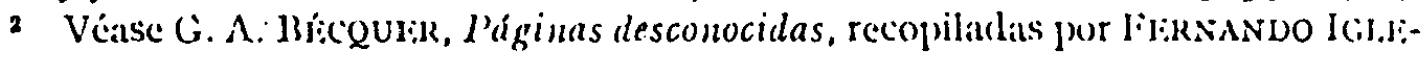
sias ligulikon, Madrid, s. a., tomo III, p. 17. Pero véase tambicin J. F. Gúmiz DI: I,As CoRTinas, La formación litcraria de Bdequer. en Revista bibliografica y documental, 1950, IV, 1). 77-99, y R. Moñrssinos, delios a Elisa Ciuillin en Insula, 1970, Dicicmbre, 11. 289, pp. I, I0, 1 I y 12. 
en $-o ́$ aguda, y asimismo precisando como fuentes más o menos probables una serie de poemas, que, tratando el mismo tema y habiendo sido relacionados con la Rima XVI por distintos investigadores, presentan en su contexto palabras agudas en $-\delta$, que la retentiva de Bécquer pudo scleccionar como asonantes de $y^{\prime}$, pronombre éste enfáticamente presente en el último verso de cada una de las tres estrofas de que consta la Rima '. Son éstos poemas de Blest Gana, Sainz Pardo, Guillermo Matta y la Rima XXVIII del mismo Bécquer ${ }^{2}$. Aceptábamos que esta Rima XXVIII debe ser anterior a la XVI, cosa que afirmaba ya Orton, $y$ suponfamos así que la misma Rima XXVIII respondería a una primera actitud de Bécquer en su trayectoria poética, que consistía en la popularización de metros cultos. Como una primera comprobación, observábamos que la Rima XXVIII, escrita en versos octosílabos, conserva ciertos recuerdos de un poema como el de G. Matta hecho en endecasilabos y heptasílabos. ¿No podría ser entonces la Rima XXVIII una. versión en octasílabos del tema para el que otros autores habian usado cndecasilabos? De acuerdo con esto, ciertas características del ritmo nos permitían mostrar cómo es posible pasar de un ritmo octosilábico al ritmo propio de la mezcla de versos endecasflabos y pentasílabos, metro en que está compuesta la Rima XVI. Si entendemos la Rima XXVIII como una primera versión o ensayo de la XVI, que procedería de ella, a la vez que de otros poemas escritos también en octosílabos, podriamos considerar que la Rima XVI responde a una segunda actitud de Bécquer en su trayectoria poética, que consistiría en una nueva estilización del metro octosilábico y de otras posibles combinaciones, que Bécquer usa por ejemplo, de versos de 8 y 5 sílabas, o incluso de versos de ocho, once y cinco. Esta segunda actitud de Bécquer se concretaría en un primer

1 Gustavo parece haber compuesto varias de sus Rimas sometiéndose a esquemas previos, sobre todo por la elección y fijación de las palabras rimadas, antes de proceder a la redacción del poema. Véase La mujer ideal, cap. $x$, nota 15 ; cap. 2, nota 37; y cap. 8, nota 13 . Sobre las rimas con pronombres personales, véase mi articulo, 'Oro' en las Rimas de G. A. Becquer, en Revisla de Eshudios Ilispánicos, 1970, nov., t. IV', num. 2., nota XI.

2 R. PAGenkd dice en su obra inédita Rimas de G. A. Bécquer. Edición cronológica y crítica, folio 297, que son demasiados los precedentes señalados a la Rima XVI y que por eso resultan sospechosos. Lsto es verdad si se piensa según uin concepto de fuente como causa y de texto infludido como efecto. Son, sin emhargo, todavia pocos los señalados, si lo que se pretende es mostrar el conjunto de las expresiones literarias que hasta Bécquer recibe el tema y compararlas con las de las Rimas, y dar idea asi de los esfuerzos que se hayan realizado para perfeccionar las formulaciones literarias del tema hasta alcanzar un verdadero valor poítico. 
cnsayo de los que precederían a su adhesión permanente a la mezcla de versos de once y siete sílabas.

Eìn nuestro libro La mujer ideal no sólo estudiábamos el metro de la Rima XVI, sino que nos referíamos también al tema, determinando las diversas posibilidades que éste of rece y que Bécquer elige para sus Rimas. Así el carácter masculino o femenino de las sensaciones descritas; igualmente los momentos que se escogen: de noche, de día, a todas horas, y la gradación en la descripción de la aproximación a la amada, en lo cual decíamos que la Rima XVI superaba a todas las demás versiones del tema, incluida la de Goethe.

A todo esto me parece importante añadir lo que dice Carlos Bousoño sobre la composición de las estrofas de la Rima XVI según un paralelismo formal, que se daba ya en los precedentes, L. I: Sanz y Blest Gana, por ejcmplo. Bécquer hace ese paralelismo más geométrico $y$ complejo que sus modelos, en él está seguido con más rigor; es un paso decisivo en un proceso que en él culmina. Esto significa, según Bousoño, que "la poesía ahíta de una repetición incesante, de la libertad excesiva y del desenfreno romántico, busca nuevas fómulas ordenadoras para 1a lírica» ${ }^{1}$.

Versiones.

Essta lucha por una renovación y ordenación 110 es sólo en Bécquer más rigurosa que en sus predecesores, sino que, como ahora mismo vamos a ver, Gustavo se esforzó por conseguir perfeccionar poco a poco sus propias composiciones paralelísticas, dotándolas además de una progresiva intensificación. Vanos a verlo en el análisis de las distintas versiones de esta Rima XVI. Al comentarla en nuestro libro La mujer ideal, nos fijábamos, como es natural, sólo en la versión definitiva, puesto que el estudio del mundo poético hay que hacerlo desde la versión definitiva. Ahora, sin embargo, podemos estudiar la evolución por la cual se llega a esa versión definitiva.

En lo que se refiere a la Rima XVI, no hay diferencias importantes entre la versión que figura en el lugar 43 del manuscrito autógrafo fundamental de las Rimas, el Libro de los gorriones, ${ }^{2}$ y la que aparece en la edición póstuma de I87I, realizada por los amigos de Gustaro. Iil texto es el mismo con ligeras variantes que se refieren a la puntua-

1 Véase Los conjunlos paraleltslicos de Bécquer, en Seis calas en la expresión lileraria española, en colaboración con Dinaso Aiosso, $4^{\text {a }}$ chición, Madrid, Credos, 1970, 1). 20 r.

Libro de los gorriones, 1115.213 .210 de la 13. N. le Madrid, fol. $5(x)$. 
ción ${ }^{1}$. Esta versión es una de las dos que se conocían hasta ahora. La otra es la publicada por el propio Bécquer en El Mluseo Universal. La versión del Libro de los gorriones, que es la definitiva, dice así:

Si al mecer las azules campanillas

de til balcoin.

crees que suspirando pasa el viento

murmurador.

sabe que, oculto entre las verdes hojas,

sispiro yo.

Si al resonar confuso a tus espaldas

vago rumor.

crees que por th nombre tc ha llamado

lejana voz,

sabe que, entre las sombras que te cercan,

tc llamo yo.

Si se turba medroso en la alla noche

lis corazón,

al sculir en tus labios $u n$ aliento

abrasador.

sabe que, aunque invisible, al lado tuyo

respiro yo.

En cambio, la publicada en El Museo Universal rezaba de este otro modo 2 .

\section{Sercnala}

Si al mecer las azules campanillas

de tub balcón.

crees que suspirando pasa el vieuto

murmusrador,

sabe que oculto entre las verdes hojas

sispiro yo.

Si se agita medroso en la alla noche

til corazón.

al sentir en tus labios $"$ n aliento

abrasador,

sabe que aunque invisible al ludo tuyo

respiro yo.

1 En la edición de 187 I aparece la Rima con su puutuación completa, tal como la transcribimos aqui. Iin el Libro de los gorriones, en cambio, faltan muchas comas, puntuación deficicnte habitual en Bécquer, y además la palabra yo del final de cada cstrofa aparece con acento ortográfico, mientras que falta ese acento en otras palabras que deberian llevarlo: balcón, corazón. Ni el pronombre yo, ni estas otras dos palibras, llevan acento en la edición de 1871 .

2 El Marseo Unizersal, 1566,1 . 151. 


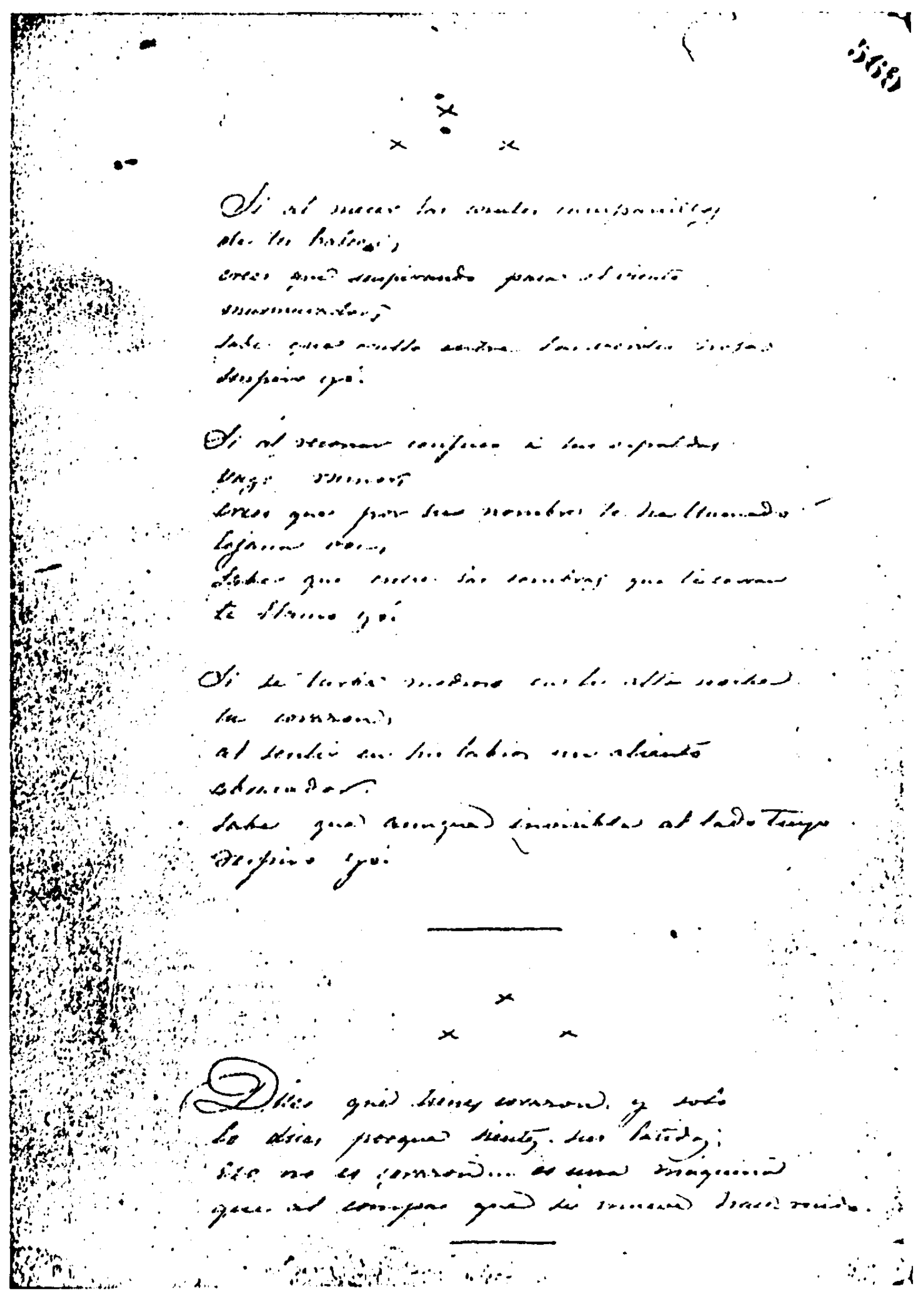

Aulógralo de la Rima d'VI de l'écquer 


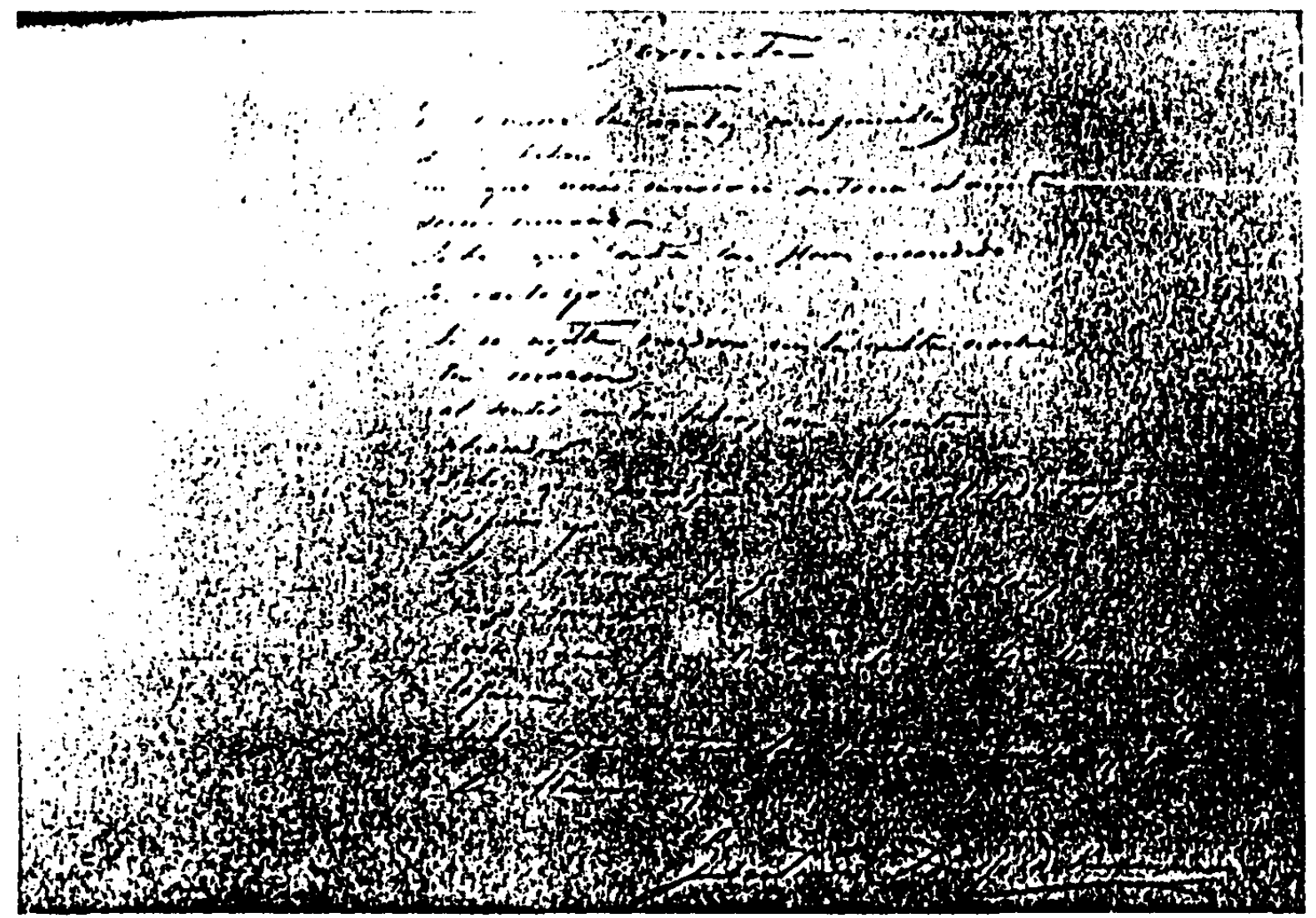

Aluógrafo incilitu de la Rima $X^{\circ} I$ que perlenece a la colecciojn de D. Pedro Martlnez (iarcimartin

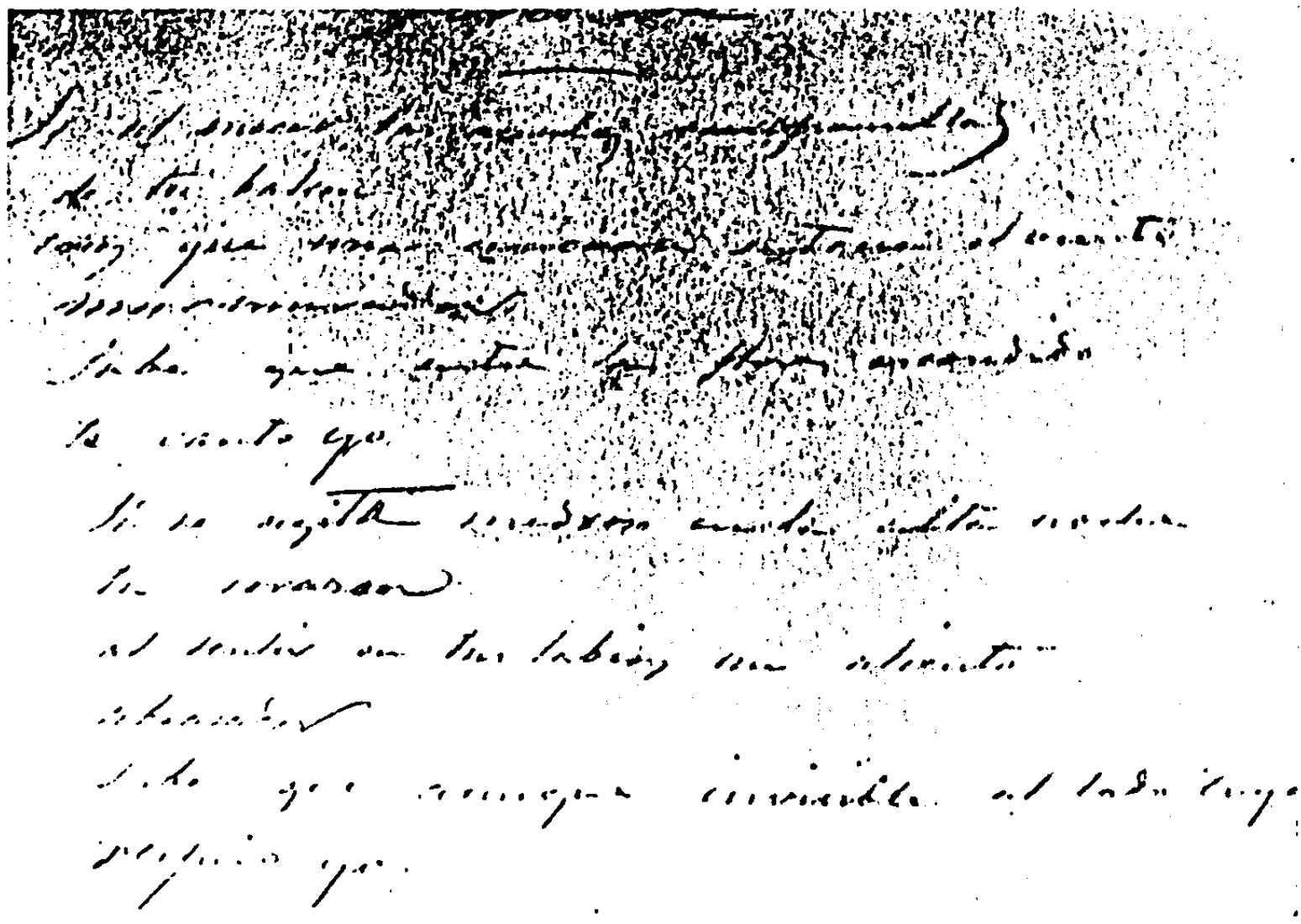

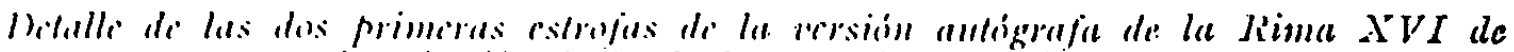
la colecioin de H. Redro Marlinez Garcimarlin 
Si al resonar confuso a tus espaldus

vago rutmor.

piensas que por th nombre te ha llamado

lejana voz.

sabe que con cl alma, noche y dia

te llamo yo.

A estas dos hay que añadir aliora otra mís, que damos a conocer aquí por primera ve\%. Se trata de un autógrafo que reproducinos fotografiado y que pertencce al coleccionista D. Pedro Nartínez Garcimartín, quien lo conserva como preciada joya de su colección ^. Es lástima que Don Pedro Martínes no haya podido decirnos sino que el autógrafo procede de un álbum de poesfas, que él adquirió en el rastro madrileño antes de la guerra de I936, probablemente en I935. I,a letra, idéntica a la del Libro de los Gorriones, la disposición de la Rima en el folio y la firma de Gustavo Adolfo D. Bécqucr, todo nos hace creer que este autógrafo becqueriano es auténtico. I a tinta está muy desvaída, pero es perfectamente legible. Por otra parte, la presencia de dos dibujos de Custavo, adcmás de otros dos de Valeriano, firmados, que se encontraban cin el mismo álbum, de donde los arrancó D. Pedro Martínez para ponerlos en marco, corrobora la autenticidad del autógrafo, por la semejanza de la firma con la de otros autógrafos y dibujos del poeta.

Esta versión dice así:

\section{Serenata}

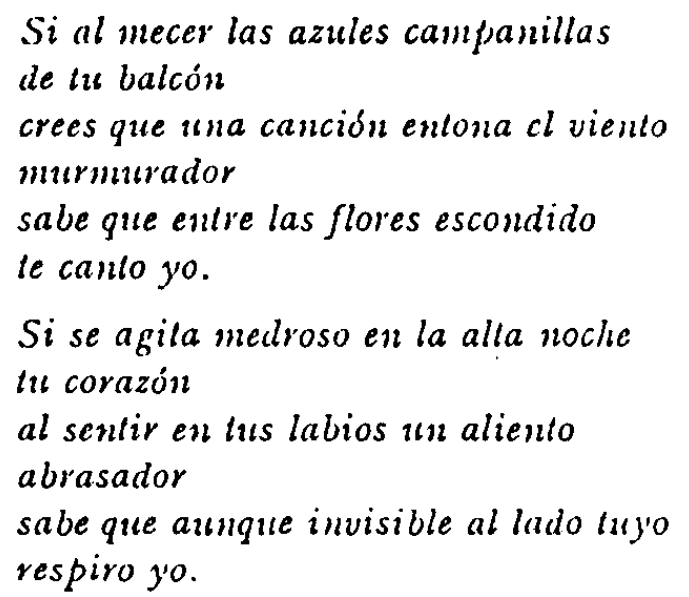

1 Iil 30 de agosto de 1964 , con ocasión de una conferencia que di en la Universidad "Maria Cristina" de Iil Isscorial, D. Pedro Martinez. me comunicó que poseia un autógrafo de una Rima de Bécquer. Meses más tarde, atendiendo a su amable invitación, D. Rafacl de Balbin y yo acudimos a su casa para ver dicho autógrafo, que resultó de la Rima XVI. Iil prof. Balbin aludió a su existencia en Revistu de Literatura, IgG4, XXVI, p. 91. He de agradecer a D. Pedro su amabilidad al permitime copiarlo y fotografiarlo. In prensa ya este artículo, recib) la noticia del fallecinicnto de $\mathrm{D}$. Pedro. Descanse en paz. 


\section{Si al resonar confuso a tus espaldas \\ vago rumor, \\ crees que por th nombre te ha llamado \\ lejana voz, \\ sabe que entre las sombras noche y dia \\ le llamo yol}

Fechas.

Al mismo tiempo que nos preguntamos por las variantes que diferencian estas tres versiones y que luego examinaremos, surge otra cuestión que se refiere al orden cronológico. Conocemos la fecha de publicación de una de estas versiones, la que apareció en El Museo Universal, el día I3 de mayo de I866, con el título de Serenata. De enero a julio de 1866 , Bécquer es director literario de El Museo Universal, responsable de la parte no firmada de la revista. Durante ese año publica en El Musco además de la Rima XVI, la XXIV, la XXIII, la V, la XI, la XV, la II $y$ la IXIX.

Conocemos también la fecha de publicación de otra de las versiones, la recogida por los amigos de Gustavo en la primera edición, póstuma, de las Rimas en $187 \mathrm{I}$, donde aparece por primera vez con el número romano XVI. Como esta versión coincide con la que aparece en el Libro de los Gorriones, podemos suponer que el poena fue compuesto en su versión definitiva después de septiembre de 1868 , probablemente en IS6g ya, cuando Bécquer, residiendo en Toledo, se dedica a reconstruir de memoria su libro de poemas, perdido al asaltar las turbas la casa de González Bravo en septiembre de $1868^{1}$. Ahora bien, si en el Libro de los Gorriones Gustavo, según él mismo dice, no hace más que recordar, se puede conjeturar que esta versión coincide con la del libro perdido. Lin este caso, como Gustavo en I 866 publica todavía la Rima tal como aparece en El Museo Universal, hay que suponer con bastante probabilidad que la versión definitiva de la Rima XVI pertenece a la época que va de majo de $I S 66$ a septiembre de $I 868$, o sea, en torno al año 1867 , año en que Bécquer vive más tranquilo, ejerciendo su cargo de fiscal de novelas, sin grandes problemas económicos y disfrutando de la amistad del poderoso González Bravo, el cual ha pedido a Gustavo que recoja sus originales para publicarlos prologados por el propio ministro de Isabel II. A este momento en que Bécquer perfila y corrige para la imprenta sus poemas, correspondería la corrección y refundición de la

1 Véase G. A. BécQui:r, Rimas. Eistudio y edición de J. M. Dínz Tabonda, Madrid. Alcalí, 1965, p. I9. Véase también RICA Brown, Béquer, Barcelona, Aedos, Ig63. p. 34I. 
Rima XVI. Atrás queda la publicación de las Leyendas, de las Cartas desde mi celda y de algunas de las Rimas en distintas revistas y periódicos ${ }^{1}$. Alora, cuando Gustavo se decide a hacer una publicación definitiva de sus versos, la adversidad, como otras veces, se ceba en el poeta y la caida de Isabel II impide la realización del proyecto.

Lin cuanto a la versión que damos a conocer ahora por primera vez, no podcmos fecharla con exactitud. Pero analizando, como luego haremos, las variantes que muestra respecto de la versión publicada en El Museo Universal, concluiremos que posiblemente sea anterior, no sólo a la fecha de publicación de esta versión de El Museo, IS66, sino a la fecha de su composición o corrección, que nos es desconocida. Naturalmente csta conclusión se queda en el terreno inseguro de la conjetura, y ante esta inseguridad podemos pensar, como alternativa, que se trata de dos versiones inmaduras anteriores a otra tercera, que es la definitiva, teniendo en cuenta, sin embargo, que de esas dos versiones inmaduras, Bécquer publicó la de El Mnseo Universal, porque quizá la consideraba superior. Ahora bien, como la publicación de la versión de El Musco Universal es de 1866 y la versión definitiva, como hemos dicho, de 1867 a 1868 , no es probable que la versión que ahora publicamos sea intermedia a las dos, sino anterior a ellas. De este modo podemos establecer un orden cronológico nuy probable, poniendo la versión que ahora damos a conocer como la primera, la publicada en El Museo Universal como la segunda y la definitiva del Libro de los Gorriones como la tercera. Conforme a este orden y con esta numeración las mencionaremos aquí.

Comparemos ahora las tres versiones entre sí.

Variantes.

In cuanto a la estructuración del motivo del tiempo, las dos primeras versiones de la Rima XVI parecen recoger dos momentos, de día, de noche, que se expresan en cada una de las dos primeras estrofas y se resumen en la tercera, noche $y$ día. En la primera estrofa no está expresa la referencia al día, pero sin duda hay luz todavía, pues se advierte el color y la forma de las flores: las azules campanillas; en la segunda estrofa está expresamente indicada la alta noche; y en la tercera aparece igualmente explícita la expresión noche $y$ dia, en ambas versiones. Es una distribución del tiempo frecuente en otros poemas

1 Véase mi edición de las Rimas, citada en la nota anterior, p. I 8 . Véase tambien RICA Brown, op. cil., pp. 310 y 323. Véase ademas $l i$. Scminidir, Tablas cronológicas de las obras de G. A. Bécquer, en IRFE, 1929, XVI, 1p. 389-399. 
que tratan el mismo tema de la proximilad del amado ${ }^{1}$, y esta coincidencia nos hace pensar que las versiones primera y segunda de la Rima XVI están dentro de una ambientación corriente del tema de la proximiclad del annado.

Según esto, el esquema de la primera versión de la Rima sería asf:

Primera estrofa: de dia, hay luz, pero el aniante está cscondido entre las flores que mueve el viento, y por eso la amada no alcanza a verlo.

Segunda estrofa: en la alla noche, el amante está al lado de la amada, pero es invisible para ella, porque no hay luz.

Tercera estrofa: noche $y$ dia, continuamente, el amante llama a la amada, pero ella no le ve, porque él siempre está cnlre las sombras, situado ell lo oscuro.

Esta referencia final a las sombras no queda clara del todo. De día la sombra no siempre hará invisible al amado. Según esto, Gustavo corrige esta inconsecuencia y en la segunda versión sustituye entre las sombras por otra expresión con el alma. Además de salvar esta imprecisión, la nueva expresión, aún siendo mucho más débil en cuanto a su efecto plástico, está más de acuerdo con el sentido del epifonema te llamo yol y con la lógica del tema, te llamo sin que estés presente, a distancia, con el alma, añadiendo una cierta intensificación, con el alma, es decir, te llamo con mucho ahínco.

En la segunda versión se transforma también toda la primera estrofa de la primera versión, cambiando los versos tercero y sexto, una canción entona el vicnto y te canto yo, por suspirando pasa el viento y suspiro j'o, más adecuados al sentido metafórico y más de acuerdo también con el paralelismo de los tres versos finales de cada estrofa, suspiro, respiro, te llamo, con lo que se mantiene el predominio final de la roz sobre los ruidos de la respiración y sobre los suspiros. Los de la primera versión te canto, respiro, te llamo, no guardan un orden ni una intensificación poética convincentes.

Una tercera variante de esta segunda versión respecto de la primera, es la sustitución de flores por verdes hojas. El motivo gana en riqueza, complejidad de formas y juego de colores. 'También parece que Bécquer logra así una mayor verosimilitud: "las flores, las campanillas, difícilmente pueden esconder al poeta, más oculto quedará sin duda entre las veriles hojas de la tupida enredadera. Hay en realidad una desviación de la atención: si tú ves moverse las flores, que son lo que más destaca de la enredadera, yo estoy junto a ellas, detrás de las hojas verdes. Pero hay todavía más, con el aumento de la sensación clara y distinta

1 Véase La mujer ideal, p. 94. 
de los colores (azules, verdes), aumenta la capacidad de visión y por tanto la alusión al día es más evidente, lograda por medio de sensaciones visuales, frente a la noche y las sensaciones táctiles de la segunda estrofa $y$ las sensaciones auditivas de la tercera.

Lìn cuanto a la sintaxis, también lay' diferencias en la segunda versión respecto a la primera. La estructura sintáctica general de la Rima se apoya sobre las palabras que cn cada estrofa inician verso: Si..., crecs..., sabc... Ahora bien, en la primera versión es: Si..., crees...; Si..., al sentir...; Si..., crees... Ein la versión segunda es: Si..., crees...; Si..., al sentir...; Si..., picnsas... Parece que en esta segunda versión, al cambiar la simetría, Bécquer ha querido intentar una intensificación, a base de los tres verbos creer, sentir y pcnsar, indicando tres momentos de un proceso, scmejantes a aquellos tres de la Rima VII: ver, ponderar, pensar ${ }^{1}$.

Comparemos ahora las dos primeras versiones con la tercera, la definitiva. En ellas se ha logrado una reestructuración más ceñida y rigurosa que afecta a varios clementos.

ITras una simple lectura, notamos que el orden de las estrofas no es el mismo en las tres versiones: la tercera estrofa de la versión definitiva (la del Libro de los Gorriones y de la primera edición) es la segunda de las otras dos versiones. Eiste cambio de orden tiene gran trascendencia para todo el poema, pues de este modo el efecto del epifonema queda alterado y con él el sentido total del poema, al ser en las dos primeras versiones te llamo yo! y en la última respiro yo! Vemos así que esta última versión responde a una mentalidad estética distinta. Eil epifonema tc llamo yo! de las dos primeras versiones nos presenta el tema dentro, como hemos dicho, de su línea tradicional, la nusma línea que manifiesta el epifonema de Nïhle des Gelicblen de Goethe, "Si estuvieras tii aqui!" ("Wärest Du da!n). El amante clama por la presencia del ser amado $y$ lo evoca en las formas de la Naturaleza. Es un sentimiento de añoranza, propio de cualquier época, aunque aquí próximo ya a la Selnusucht romántica ${ }^{2}$. Ein cambio, la tercera versión de la Rima XVI lo que busca es insistir en la insinuación de que todo lo que está alrededor de la amada lia de evocar la cercanía inmediata del amado

1 Véase mi artículo Análisis estilistico de la Rima rII de Bécquer, en Boletin de la Sociedad Castelloncuse de Cullura, r959, enero-marzo, t. XXXV, pp. 76-80.

- Recuérdese la afirmación de A. W. Scmiteger en sus lecciones vienesas: "Die Pocsie der Alten war die des Besitzes, die unsrige ist die der Sehnsucht; jene steht fest auf dem Boden der Gegenwart, diese wiegt sich zwischen Erinnerung und Ahndung». Citado por P. KLUCKIrons. Das Ideengut der deutschen Romantik, 3. Auflage, Tübingen, I953, p. I85. 
ausente. No basta el recuerdo, ni el pensamiento, ha de llegarse a la vivencia casi espectral de la presencia invisible del amado, para lo cual él se hace a sí mismo intérprete de las sensaciones de ella. Para lograr este efecto, Bécquer sustituye la formulación temporal, tan esquemática, de dia, de noche, noche y día, por una sucesión temporal que va creciendo en intensidad y que queda además enhebrada en otra seriación espacial igualmente intensificada por la emoción. Al deseo de expresar estas dos intensificaciones se debe la alteración del orden de las estrofas.

En cuanto al tiempo, la versión definitiva de la Rima XVI lo gradúa de una manera mucho más sutil y da pie a una interpretación más verosímil, describiendo un proceso continuado, en vez de hacer una división tan racionalizada como la de las dos primeras versiones. En la primera estrofa hay colores, azul y verde, y por tanto, como hemos dicho antes, se refiere al día, hay luz todavía; en la que era tercera estrofa en las dos primeras versiones, ahora colocada en segundo lugar, se suprime la referencia temporal de resumen, noche y dia, y se repone la expresión cnlre sombras, que figuraba en la primera versión y que el propio Bécequer suprinio en la segunda. Lista referencia a las sombras indica quizá la jenumbra del crepúsculo, quizá el primer momento de la noche. Iin la tercera estrofa se cita ya concretamente la alla noche, las altas horas de la noche. La progresión parece ser, por tanto, de lo luminoso a lo oscuro, del día a la noche, en tres momentos sucesivos: antes de anochecer, al anochecer, después de anochecido; o bien, al atardecer, al anochecer, de noche; o más simplemente, de día, al anocliecer, de noche.

En cuanto al espacio, hay que deducir de todo el contexto que se trata del dormitorio de ella, sobre todo por las referencias concretas de tú balcón y en la alla noche. Al desaparecer la expresión de resumen temporal, noche y día, se logra una unidad de lugar, de escenario, en la que se dan estos tres momentos sucesivos que indicamos. Las referencias espaciales son, por lo demás, relativas a ella, la amada, figura única que constituye el centro de la escena: ella presiente al amado primero un poco distante, en el balcón, escondido entre la enredadera, o sea delante; más tarde lo imagina a sus espaldas, es decir detrás, pero más próximo, y alrededor porque la referencia a las sombras disminuye la dimensión espacial: entre las sombras que te cercan; por último, lo siente más cerca todavía, nota su aliento en los labios: él está inmediato, al lado de ella. En las dos primeras estrofas el amado está perdido, envuelto, escondido entre las cosas (las hojas, visibles, o las sombras, que ocultan las cosas) que rodean a la amada; en la tercera estrofa, en cambio, la referencia ya no es a las cosas, que en la oscuridad total han desa- 
parecido, incluso como sombras, sino a la propia amada, al lado tuyo. En la última versión, creo, queda claro que las referencias espaciales destacan sobre las temporales, al contrario que cn las dos versiones primeras, en que veíamos destacarse más el esquema temporal. Basta fijarse en la introducción de la oración relativa, que le cercan, referida a las sombras. Con ella se aviva la sensación espracial y se anortigua el efecto del verso le llamo yo que aciba la segunda estrofa de esta tercera version, pues ya no puede ser uni llanada a distancia, sino cercana, pero hecha en voz tan baja que la amada, interpreta lo contrario: lejana voz:

Én este escenario de doble dimensión, espacial y temporal, se esparcen las sensaciones de la amada. Lil amado las sintetiza, corrigiendo la interpretación que la amada les da en las dos primeras estrofas (crcos) - dándoles una interpretación propia y cierta (sabe), que destaca especialmente en la tercera estrofa: él mismo es la meta y el sentido único de ellas. La serie de sensaciones de la amada que aparecían en las dos primeras versiones se manticnen en la tercera, pero con nuevo orden y nueva intensificación. Lin la primera estrofa se trata de sensaciones visuales sobre las que se superponen otrats anditivas: sobre el movimiento de las flores, el suspirar del viento; en la segunda estrofa, cn cambio, no lay sensación visual, sino que se superpone una sensación auditiva a otra también auditiva: la lejana voz sobre el vago rumor "; en la tercera estrofa, no hay ya sensaciones ni visuales ni auditivas, sino sólo una táctil: al sentir en tus labios un aliento abrasador, el amado, que no ha sido visto, ni oido claramente, es claramente sentido. En cuanto a la interpretación de estas sensaciones, en la primera estrofa es más verosímil, aunque se parte de una apreciación casual a que se llega casi distraidamente: si al ver mecerse las flores, crees que es el viento que suspira, no es él, soy yo. Hablar del suspirar del viento supone ya una personificación poética que se da en la lengua normal, y entonces referirlo a una persona es cosa bien verosímil. En la segunda estrofa la interpretación es más exaltada, menos verosimil, un rumor confuso y vago se interpreta como lejana voz. La identificación del yo del amado y sus acciones se realiza no con algo objetivo, como en la primera estrofa, mis suspiros son como los del viento, sino con algo que tiene poca base objetiva, con la lejana voz que es apreciación subjetiva de la amada; en este caso, la interpretación de él, esa voz es la mia, está más cerca de lo que es mera sensación de ella. Por último, en la tercera estrofa ya. no hay siquiera apreciación de la amada, y la interpretación del amado

1. Una sensación anditiva que se distingue sobre otras auditivas también, pero más confusas, se expresa en la Rima $I \mathrm{XX}$, vs. is y 16. 
se funda en la misma sensación real, directa, de ella, que siente un aliento, no algo que ella interpreta como aliento; esa sensación ocurre al mismo tiempo que una gran turbación interna. De aquí, de esta penetración en el interior de la amada, que ocurre cuando la amada se recoge sobre si misma, se deriva la sustitución del verbo agilarse, por el verbo turbarse, el primero más cerca de lo puramente físico, cl segundo más próximo a lo psíquico y aún moral. Turbar, por lo demás, es palabra no rara en otros textos que tratan el mismo tema.

La amada es el receptor de todas estas sensaciones; sin embargo, de los sentidos que las perciben, ojos, ódos, labios, sólo estos últimos se mencionan, con lo que parece que se les quiere dar prioridad como órganos de comunicación directa, que no tienen necesidad de interpretación, al contrario de los ojos y los oídos. No hay que olvidar que los labios son el órgano del beso y que el beso, como expresión de la relación amorosa, representa la unión, la comunicación plena de dos seres, porque en el beso nocturno se da la unión de alma y cuerpo y, al mismo tiempo, la unión de amado y amada, potenciándose todas las fuerzas del subconsciente, de aquello que los románticos llamaban todavia $N$ achtscilen der Nalur ${ }^{3}$. La Rima XVI, de modo distinto a otros poemas que tratan el tema de la proximidad del amado, no recoge la consumación del beso, sino que solamente la insinúa como hecho fundamental y culminante, cuya inminencia se presiente en el momento solemne de la alta noche. En realidad, con esta unicidad de un tiempo y un espacio, lo que se da es la abreviación de los tiempos y la reducción de los espacios al momento y punto del beso. Más allá de las coordenadas de tiempo y espacio, la tercera estrofa evoca la pura relación personal, yo/tii, ya que, como decían los románticos, la individualidad, entendida como núcleo metafísico de la persona, no está condicionada por el tiempo y el espacio; precisamente por eso, por la intensidad del momento amoroso que tiende a perpetuar la unión de dos individualidades, se trascienden las fronteras terrenales y se conecta con lo más intimo de la naturaleza, con el sentido más hondo del universo, hasta dar entrada a la actividad cósmica; recuérdese la dimensión cósmica del beso en la Rima IX. Así, pues, no deja de ser verdad lo que en otra parte decíamos, o sea que "domina toda la Rima XVI una impresión de impersonalidad que deja patente al principal protagonista: lo cósmico. Esa impersonalidad se apoya sobre todo en los verbos (resonar, se turba), principalmente en el primero (meccr), cuyo sujeto apenas si llega a precisarsen ${ }^{2}$. Este

1 Véase P. KLucknom, op. cil., pp. 37 y 4 I.

2 Ibidem, p1). 57 y 73 . Véase también La mujer ideal, 1) 93. 
efecto se consigue sobre todo por la inversión de las frases y la trasposición del sujeto con fuerte hipérbaton. Con técnica muy similar, se produce en la tercera estrofa un trastrueque del paralelismo sintáctico, que antepone la expresión del movimiento del corazón, es decir que parte de lo más íntimo de la realidad expresada en la Rima: el corazón de la amada, al revés que en la primera estrofa, que partía de lo más externo, las campanillas, el balcón etc., o sea de la fachada exterior del escenario de la Rima. Iin este aspecto de la estructura sintáctica se abandona en la tercera versión el intento de construir una gradación a base de los tres términos: creer, sentir, pensar, puesto que el valor de piensas es en este caso prácticamente igual al de crees, o menor incluso, y en cambio, con la alteración de las estrofas, se llega a la construcción crecr, creer, sentir, que pone sobre las sensaciones visuales y auditivas, necesitadas de interpretación (crecs), la sensación táctil, paradójicamente más perfectamente comunicativa, de acuerdo con aquellos tres pasos que distinguía Novalis, vcr, oir, sentir, y que abrian el ser a una vida superior, más allá del sueño, como también más allá de la muerte ${ }^{1}$.

Ia proximidad clel amado está, pues, según vemos, claramente matizada y gradualmente intensificada en la Rima XVI. lis cada ve\% mayor en su avance dentro de la oscuridacl, con un momento crítico, el de la segunda estrofa, en (que ella, la amada, se siente incluicta, aludida, cada vez más estrechamente cercada y con menos posibilidades de reacción en sus sentidos: el amado "se sitúa siempre en el límite mismo a que en cada momento llegan los sentidos" de ella ${ }^{2}$. Lise momento crítico, crejuscular, de la segunda estrofa, justificado desde el más hondo sentido del poema, se logra por la alteración del orden de las estrofas que antes señalábamos, pues deja el orden definitivo de los epifonemas de las estrofas en la secuencia, suspiro, te llamo, respiro. La inquietante llamada, que muestra, como antes decíamos, la exaltación del ánimo de ella, queda así colocada entre el convencional suspirar y el mero respirar, movimiento puramente fisiológico, que presenta la vida externa reducida al mínimo, en el momento de la máxima turbación interna. Lisa transparencia del mundo interior ocurre precisamente cuando la persona se ha entregado al sueño ${ }^{3}$. De este modo las tres estrofas de la Rima XVI parecen corresponderse con los tres grados del sueño magnético, que señalaban las tcorías psicológicas del Romanticismo. In el primer

1 Véase P. Kriuckilonis, p. 43.

2 Véase La mujer ideal, p. 93.

3. Véase la misma concepción poćtica en la Rima XXVII, especialmente cul lil cstrofa sćptima. 
grado, la persona está despierta y mantiene su relación con el mundo exterior; en el segundo, está medio dormida con los sentidos medio cerrados, sobre todo el de la vista; en el tercero, está dormida y situada en el límite de dos mundos, junto a la puerta que abre paso a un ser y un estar mejor ${ }^{1}$. Bécquer perfecciona este esquema, al expresar con mayor precisión que, con la pérdida de las sensaciones visuales por efecto de la oscuridad, se aumenta la tensión anímica hasta la exaltación, a la vez que se afinan las facultades de percepción auditiva hasta oir voces lejanas por encima de otros ruidos y sonidos. La finura del análisis de Bécquer llega a producir un "adelgazamiento inverosímil de las sensaciones, sin que pierdan vigor ni plasticidad, gracias a la localización altamente evocadora de cada una de ellas" ${ }^{2}$.

La nueva versión de la Rima XVI que publicamos viene a demostrarnos los tanteos y esfuerzos de Gustavo por llegar a la madurez de su creación poética, al mismo tiempo que nos indica su voluntạd de perfeccionamiento continuo, que se expresa en aquella frase suya de escribir como quien supera una dificultad ${ }^{3}$. Aunque se consideren válidos los testimonios que nos dicen que para I860 ó I86I estaban ya compuestas la mayoría e incluso la casi totalidad de las Rimas, cosa que muy bien podría afectar a la primera versión, la que aquí damos a conocer, de la Rima XVI 4, eso no quiere decir, sin embargo, que Gustavo no prosiguiese una labor de perfeccionamiento en los años siguienres, al prepararlas para su publicación, bien en revistas, bien en el libro perdido, o al rehacerlas de memoria en el Libro de los Gorriones, o al corregirlas en este mismo libro una vez ya trasladadas a él, si es que esas correcciones son del todo o en parte de Bécquer. De todos modos la madurez de la tercera versión, la definitiva, de la Rima XVI, se pone de manifiesto en el hecho de que no sufre variación al ser publicada en la primera edición de 1871 .

Ese ansia de perfeccionamiento nos parece muy importante, porque;

1 Véase I. Iíucknom, $o p$, cit., p. 4 r.

2 Véase La mujer ideal, p. 93.

3 Véase la recensión de La Soledad de A. Ferrín, en G. A. BEceurer, Obras Completas, Madrid, Aguilar, 1969, p. I 89 . Recuérdense también los versos de la Rima XV: "Ansia perpetua de algo mejor / eso soy you.

- Véase el caso quizá paralelo de la Rima XXVII, por tantas razones enlazada con la XVI: se publicó en La Gaceta Literaria en 1863 en versión muy distinta a la del Libro de los gorriones. Recientemente RAFari, Montesinos ha publicado una versión anterior con variantes y fechada en mayo de 1860 . Véase Miindo Hispdnico, número extraordinario de lomenaje a Bécquer, 1970, noviembre, mimero 272, p. 65 . 
como hemos intentado hacer ver, acusa una evolución, un cambio notable en la mentalidad estética de Gustavo. Este cambio supone un progreso hacia unas formas que podemos llamar posrománticas - todavía nos parece excesivo llamarlas realistas-, puesto que suponen la elaboración del mundo romántico en el sentido de una mayor concreción, una mayor verosimilitud y una mayor interiorización. Con este cambio se traza a la vez un camino que va hacia una evocación más plástica y hacia una poesía esencial montada sobre un juego de pronombres personales, que responde al mismo esquema inicial de palabras rimadas y que se mantiene con decidida voluntad y muy pocas variaciones.

Dentro de la trayectoria del mundo poético de Bécquer, la Rima XVI está en el paso de la visión de la mujer en el horizonte de la naturaleza a la contemplación de ella en el recinto del dormitorio ${ }^{1}$. La naturaleza queda aquí reducida a un minimo, a mera orla externa, mientras aumentan, en cambio, las referencias a la anada, todo queda situado en relación a ella, hasta concentrarse en sus labios y penetrar hasta su corazón, como centro de todo ese ámbito que ella ocupa totalmente.

Juan makí dízz 'iabonda.

1 Véase La mujer ideal, p. 157. 